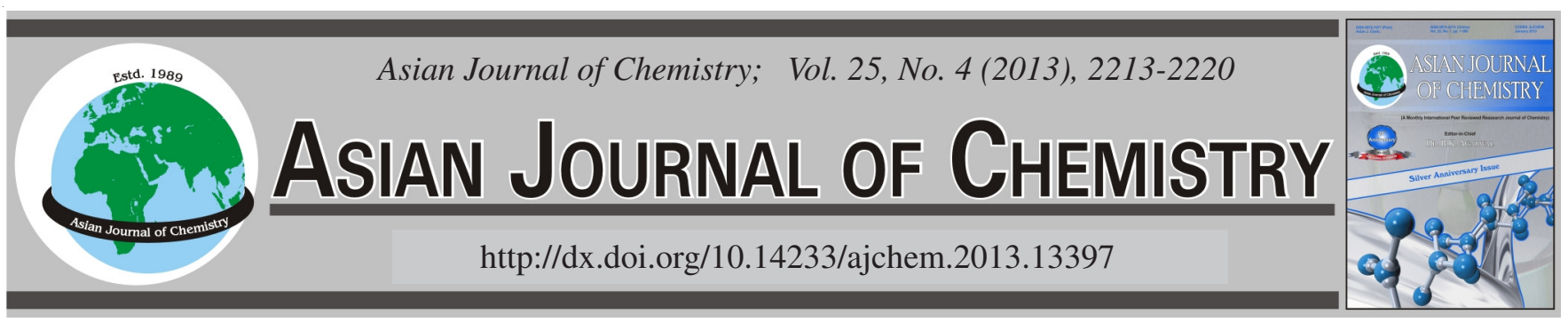

\title{
Effect of Bifunctional Isocyanate Linker on Adsorption of Chromium(VI) Diphenylcarbazide Complex onto $\beta$-Cyclodextrin
}

\author{
Sharifah Mohamad ${ }^{1, *}$, Nurul Huda Mohd Yusof $^{1}$ and Saliza Asman ${ }^{1,2}$
}

${ }^{1}$ Department of Chemistry, Faculty of Science, University of Malaya, 50603 Kuala Lumpur, Malaysia

${ }^{2}$ Department of Science and Mathematics, Faculty of Science, Technology and Human Development, University Tun Hussein Onn Malaysia, 86400, Parit Raja, Johor, Malaysia

*Corresponding author: Fax: +60 37967 4193; Tel: +60 3 79676751; E-mail: sharifahm@um.edu.my

(Received: 6 January 2012;

Accepted: 17 October 2012)

AJC-12314

\begin{abstract}
Two polymers has been synthesized using bifunctional reagents of isocyanate group as crosslinking agent, which are $\beta$-cyclodextrin polymer crosslinked hexamethylene diisocyanate ( $\beta$-CDP-HMDI) and $\beta$-cyclodextrin polymer crosslinked toluene-2,4-diisocyanate ( $\beta$-CDP-TDI). The adsorption of $\mathrm{Cr}(\mathrm{VI})$ ions from aqueous solution by $\beta$-cyclodextrin polymer $(\beta-\mathrm{CDP})$ as an adsorbent was studied in batch adsorption experiments. The method was based on the complex of $\mathrm{Cr}(\mathrm{VI})$ with 1,5-diphenylcarbazide (DPC) in acidic solution loaded on $\beta$-CDP-HMDI and $\beta$-CDP-TDI adsorbents. The adsorbents were characterized using Fourier transform infrared spectroscopy. The adsorption isotherm and kinetics of $\mathrm{Cr}(\mathrm{VI})$-DPC complex onto both of $\beta$-cyclodextrin polymer were studied. It showed that the Langmuir isotherm is better fit described the adsorption process for $\beta$-CDP-HMDI, while Freundlich isotherm is better fit for $\beta$-CDPTDI. The pseudo second order kinetic model represented the adsorption process for both of $\beta$-cyclodextrin polymer adsorbents. However, the rate constant of adsorption by $\beta$-CDP-TDI was lower than $\beta$-CDP-HMDI. The thermodynamic study showed that the enthalpy $\left(\Delta \mathrm{H}^{\circ}\right)$ value of $\beta$-CDP-TDI was higher than $\beta$-CDP-HMDI, indicated that $\beta$-CDP-TDI has strong chemical bond with $\mathrm{Cr}(\mathrm{VI})$-DPC. Furthermore, the value of free energy $\left(\Delta \mathrm{G}^{\circ}\right)$ and and entropy $\left(\Delta \mathrm{S}^{\circ}\right)$ showed that $\beta$-CDP-TDI was more absorbable of Cr(IV)-DPC complexes than $\beta$ CDP-HMDI. From these results, it was revealed that cross-linking agent is the main factor that contribute in the adsorption process of $\mathrm{Cr}(\mathrm{VI})$-DPC complex onto $\beta$-cyclodextrin polymer.
\end{abstract}

Key Words: $\beta$-Cyclodextrin, Bifunctional cross-linking agent, Isocyanate, Adsorption, $\mathrm{Cr}(\mathrm{VI})$.

\section{INTRODUCTION}

Chromium is one of the toxic heavy metals and is a major pollutant in wastewater. The chromium is originates from widespread use in various industries such as metallurgical, refractory and chemical. Chromium exists in two stable oxidation states, $\mathrm{Cr}(\mathrm{III})$ and $\mathrm{Cr}(\mathrm{VI})$. Both of them have drastically different charge, physicochemical properties as well as chemical and biochemical reactivity ${ }^{1}$. Cr(VI) exerts toxic effects on biological systems and exposure to hexavalent $\mathrm{Cr}$ compounds leads variety of clinical problem. It can cause perforation of the nasal septum, asthma and bronchitis. It also causes health disorders, such as vomiting and hemorrhage ${ }^{2}$. It is known to be carcinogenic and mutagenic which induces dermatitis. The maximum level permitted in wastewater is $5 \mathrm{ppm}$ for $\mathrm{Cr}$ (III) and 0.05 ppm for $\mathrm{Cr}(\mathrm{VI})^{3,4}$. Due to the extreme toxicity of $\mathrm{Cr}(\mathrm{VI})$, its selective determination and removal from wastewater is of particular concern.

Several methods have been developed for removal of $\mathrm{Cr}(\mathrm{VI})$ from aqueous solution such as chemical precipitation, chemical oxidation or reduction, filtration, ion exchange, electrochemical treatment, application of membrane technology and evaporation recovery ${ }^{5}$. However, these technology processes have considerable disadvantages including incomplete metal removal, necessity for expensive equipment and monitoring system, high reagent, energy requirement or generation of toxic sludge or other waste products that require disposal ${ }^{6}$. Compared with several methods, adsorption is one of the most economically favourable and a technically easy method, more effective and widely used technique ${ }^{7}$ for water treatment in terms of flexibility and simplicity of design, ease of operation and insensitivity to toxic pollutants ${ }^{8}$. It is a physiochemical wastewater treatment process, which is gaining prominence as a means of producing high quality effluents, which are low in metal ion concentrations.

Many different types of adsorbents were used for selective determination and removal of chromium species from water samples in adsorption technique includes activated carbon ${ }^{9-11}$, industrial by-products ${ }^{12}$, biomass ${ }^{13}$, clays $^{14}$ and agricultural 

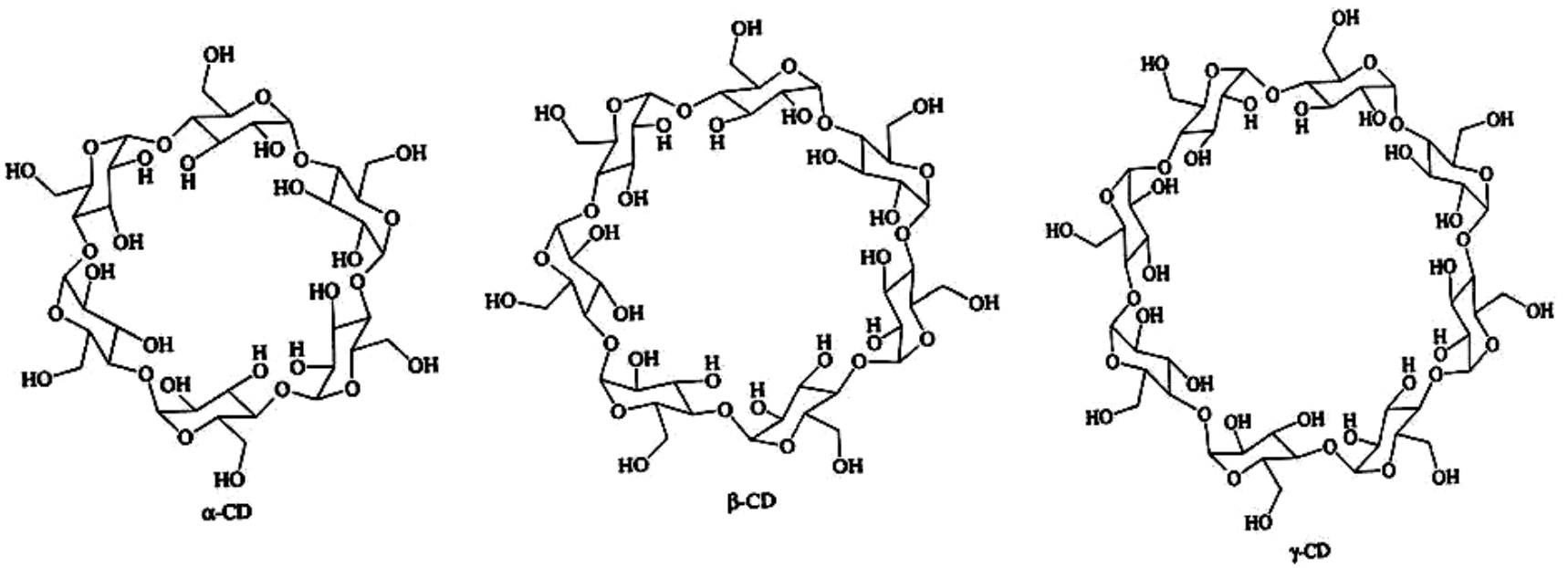

Fig. 1. Chemical structure of types of cyclodextrins ${ }^{21}$

waste ${ }^{5,15-17}$. Recently, much attention has been focused on biopolymers and natural molecules ${ }^{18,19}$ such as chitosan ${ }^{20}$, starch or $\beta$-cyclodextrin ( $\beta$-CD) as adsorbents.

Cyclodextrins are a family of cyclic oligosaccharides composed of $\alpha-(1,4)$ linked glucopyranose subunits. There are three main types of cyclodextrin; $\alpha-\beta$ - and $\gamma$-cyclodextrin, which contain 6,7 and 8 of glycopyranose unit, respectively (Fig. 1). They possess a cage-like supramolecular structure, which is the same as the structure formed from cryptands, calixarenes, cyclophanes, spherands and crown ethers ${ }^{21}$. It is a torus-shaped cyclic oligosaccharide made up of seven $\alpha$ 1,4-linked-D-glucopyranose units. The C-2-OH group of one glucopyranose unit can form a hydrogen bond with the C-3$\mathrm{OH}$ of the adjacent glucopyranose unit ${ }^{22}$. Among these three types, $\beta$-cyclodextrin is most accessible and low-priced ${ }^{23}$. However, its solubility in water makes it inconvenient to use as adsorbent ${ }^{24}$, therefore, $\beta$-cyclodextrin polymer may offer better alternatives.

There are many several application of $\beta$-cyclodextrin polymer as adsorbent is applied to adsorb pollutants such as removal of dyes ${ }^{25-29}$ and aromatic compounds ${ }^{30-37}$. The $\beta$ cyclodextrin can be cross-linked by a reaction between the hydroxyl groups of the chains with a coupling agent to form water-insoluble cross-linked network ${ }^{28,37}$. The general method for synthesis of water-insoluble $\beta$-cyclodextrin polymer is by crosslinking the hydroxyl groups of $\beta$-cyclodextrins with bi- or multi-functional molecules to form a stable crosslinked network. The bi- or multi-functional molecules used are normally called crosslinking agents. Epichlorohyrin ${ }^{38-42}$, diisocyanates ${ }^{43-45}$, polycarboxylic acids ${ }^{46-49}$ and anhydrides ${ }^{50,51}$ have been reported to be effective crosslinking agents.

In this study, two $\beta$-cyclodextrin polymer adsorbents which are $\beta$-cyclodextrin polymer cross-linked with 1,6hexamethylene diisocyanate ( $\beta$-CDP-HMDI) and $\beta$ cyclodextrin polymer cross-linked with toluene-2,4diisocyanate $(\beta-C D P-T D I)$ has been used as sorbents for removal of $\mathrm{Cr}(\mathrm{VI})$ where the method is based on the complex reaction of 1,5-diphenylcarbazide (DPC) (Fig. 2) with $\mathrm{Cr}(\mathrm{VI})$ produces diphenylcarbazide complex-chromium at acidic condition. The sorption behaviours of the two polymers were compared through experimental investigations. The influence of several operating parameters such as initial concentration and contact time was also investigated. The adsorption isotherm and kinetics of $\mathrm{Cr}(\mathrm{VI})$-DPC complex onto both of $\beta$-cyclodextrin polymer were studied to identify the possible mechanism of the sorption process. The aim of the present work was to investigate the effect of bifunctional isocyanate linker on adsorption of chromium (VI)- diphenylcarbazide complex onto $\beta$-cyclodextrin polymer.

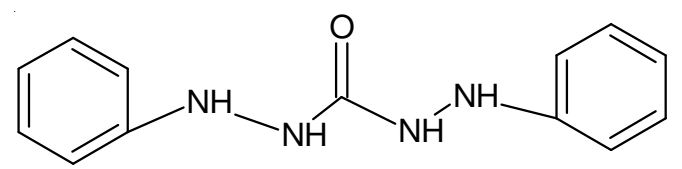

Fig. 2. 1,5-Diphenylcarbazide

\section{EXPERIMENTAL}

A model analyst 400 (Perkin Elmer, Germany) flame atomic absorption spectrometry equipped with an air acetylene burner and chromium electrodeless discharge lamp was used for the determination of chromium. The $\mathrm{pH}$ measurements were performed with Eutech model (Singapore) of $\mathrm{pH}$ meter. FTIR spectra of the polymers were recorded using FTIR spectrophotometer (Perkin Elmer, United Kingdom) in $\mathrm{KBr}$ pellets.

1,5-Diphenylcarbazide (Acros) solution was prepared daily by dissolving appropriate amount of 1,5-diphenylcarbazide (Sigma) in $25 \mathrm{~mL}$ of acetone (Fisher). Cr(VI) stock solutions (1000 mg/L) were prepared from $\mathrm{K}_{2} \mathrm{CrO}_{4}$ (Merck), $\mathrm{H}_{2} \mathrm{SO}_{4}(37 \%)$ (Fisher) were used. $\beta$-cyclodextrin (Acros), 1,6-hexamethylene diisocyanate (HMDI) (Sigma), toluene2,4-diisocyanate (TDI), dimethylformamide, acetone were purchased from Acros and all other chemicals used were analytical grade. The ultra pure water was used during experiment.

Synthesis of $\beta$-cyclodextrin polymer ( $\beta$-CDP-HMDI and $\boldsymbol{\beta}$-CDP-TDI): $\beta$-Cyclodextrin polymer was synthesized according to the method of Baskhar et al. ${ }^{52}, 5 \mathrm{~g} \beta$-cyclodextrin was dissolved with $15 \mathrm{~mL}$ of dimethylformamide in $500 \mathrm{~mL}$ of round bottom flask at room temperature. A calculated amount of cross-linker 1,6-hexamethylene diisocyanate or toluene-2,4-diisocyanate was added drop wise into the mixture. 
The mixture of $\beta$-cyclodextrin and 1,6-hexamethylene diisocyanate or toluene-2,4-diisocyanate was prepared in ratio $1: 10$ and $1: 7 \mathrm{mmol}$, respectively. The mixture solution was stirred at $70^{\circ} \mathrm{C}$ for $4 \mathrm{~h}$. Finally, the polymer was precipitated when added and washed with large excess of methanol. The polymer was filter off by suction and dried at oven overnight at $80^{\circ} \mathrm{C}$. The polymers were characterized using FT-IR with a $\mathrm{KBr}$ pellet technique.

$\mathrm{Cr}$ (VI)-1,5-diphenylcarbazide complex solution preparation: The formation of $\mathrm{Cr}(\mathrm{VI})-\mathrm{DPC}$ complex was prepared by adding $20 \mathrm{~mL}$ of known concentration of $\mathrm{Cr}(\mathrm{VI})$ in acidic medium of $\mathrm{H}_{2} \mathrm{SO}_{4} 0.008 \mathrm{~mol} / \mathrm{L}$ into $3 \mathrm{~mL}$ of 1,5-diphenylcarbazide $(0.0025 \mathrm{M})$. It was left for about 10 minutes to make sure the formation of complex reaction was complete.

Adsorption experiments: Adsorption capacities and kinetics were conducted using the batch method. Experimental data were obtained at of 25,45 and $65{ }^{\circ} \mathrm{C}$ by varying the concentration of $\mathrm{Cr}(\mathrm{VI})-\mathrm{DPC}$ complex in aqueous solution from 10 to $30 \mathrm{mg} / \mathrm{L}$. In each experiment, a series of $20 \mathrm{~mL}$ of $\mathrm{Cr}(\mathrm{VI})-\mathrm{DPC}$ complex was added to $0.05 \mathrm{~g}$ of $\beta$-CDP-HMDI or $\beta$-CDP-TDI at a known initial concentration. The mixture was then stirred in a water bath on a constant agitation speed of $180 \mathrm{rpm}$ continuously at different temperatures. Studies were conducted at various time intervals to determine when adsorption equilibrium was reached. The solid phase was separated by filtration. The suspension was subjected and the final concentration of filtrate was determined by flame atomic absorption spectrometry.

Adsorption capacity of adsorbent was calculated from the equation given by:

$$
\mathrm{Q}=\frac{\left(\mathrm{C}_{\mathrm{o}}-\mathrm{C}_{\mathrm{f}}\right) \mathrm{V}}{\mathrm{m}}
$$

where, $\mathrm{Q}$ is the adsorption capacity of adsorbent $(\mathrm{mg} / \mathrm{g}), \mathrm{C}_{\mathrm{o}}$ and $C_{f}$ are the initial and final concentration of the chromium(VI) solution $(\mathrm{mg} / \mathrm{L})$ respectively and $\mathrm{m}$ is the mass of $\beta$-CDP-HMDI or $\beta$-CDP-TDI (g).

\section{RESULTS AND DISCUSSION}

Fourier transform infrared spectroscopy: $\beta$-Cyclodextrin, $\beta$-CDP-HMDI, $\beta$-CDP-TDI has been characterized using Fourier transform infrared spectroscopy. The band assignments related to the FT-IR analyses of the $\beta$-cyclodextrin, $\beta$-CDPHMDI and $\beta$-CDP-TDI are given in Table- 1 . Absence of peak at $2270 \mathrm{~cm}^{-1}$ (corresponding to isocyanate group) shows that completion of reaction. The bands at $2925 \mathrm{~cm}^{-1}$ and $2933 \mathrm{~cm}^{-1}$ correspond to the methylene group in 1,6-hexamethylene diisocyanate, while the bands at $1602 \mathrm{~cm}^{-1}$ and $1457 \mathrm{~cm}^{-1}$ are represent the aromatic group in toluene-2,4-diisocyanate. The adsorption band at $1253 \mathrm{~cm}^{-1}$ could be attributed to the $\mathrm{C}=\mathrm{O}$ characteristics vibrations of aliphatic polyurethane. The $856 \mathrm{~cm}^{-1}$ peak considered for $\alpha-(1,4)$ glucopyranose in $\beta$ cyclodextrin.

Adsorption experiments: Adsorption isotherm expresses the relationship between mass of adsorbate per unit weight of adsorbent and liquid phase equilibrium concentrations of adsorbate. Langmuir and Freundlich isotherm are the most frequently used equations to plot data corresponding to adsorption from solution measurements ${ }^{20,27}$. The quality of the isotherm fit to the experimental data is typically assessed based on the magnitude of the correlation coefficient for the regression: i.e. the isotherm giving an $\mathrm{R}^{2}$ value close to unity is deemed to provide the best fit $^{6}$.

\begin{tabular}{|c|c|c|}
\hline \multicolumn{3}{|c|}{$\begin{array}{c}\text { TABLE-1 } \\
\text { KEY IR FREQUENCIES WITH ASSIGNMENTS }\end{array}$} \\
\hline Samples & Wavelength $\left(\mathrm{cm}^{-1}\right)$ & Assignments \\
\hline \multirow[t]{2}{*}{$\beta$-cyclodextrin } & 856 & $\alpha$-(1,4)glucopyranose \\
\hline & 1029,1100 & $\mathrm{C}-\mathrm{OH}$ strectching vibration \\
\hline \multirow[t]{5}{*}{$\beta$-CDP-HMDI } & 1253 & $\begin{array}{l}\mathrm{C}=\mathrm{O} \text { vibrations of aliphatic } \\
\text { polyurethane }\end{array}$ \\
\hline & 1569 & NHCO, carbamate linkage \\
\hline & 3420,1700 & $\mathrm{NH}$ and $\mathrm{C}=\mathrm{O}$ \\
\hline & 2270 & $\begin{array}{l}\text { Absence of isocyanate group } \\
\text { (completion of reaction } \\
\text { polymerization) }\end{array}$ \\
\hline & 2925,2933 & $\begin{array}{l}\mathrm{CH}_{2} \text { assymmetric stretching } \\
\text { vibration from methylene } \\
\text { crosslinker }\end{array}$ \\
\hline \multirow[t]{5}{*}{$\beta$-CDP-TDI } & 1227 & $\begin{array}{l}\mathrm{C}=\mathrm{O} \text { vibration of aromatic } \\
\text { polyurethane }\end{array}$ \\
\hline & 1602,1457 & Aromatic group in TDI \\
\hline & 1541,1655 & NHCO, carbamate linkage \\
\hline & 3393,1700 & $\mathrm{NH}$ and $\mathrm{C}=\mathrm{O}$ \\
\hline & 2270 & $\begin{array}{l}\text { Absence of isocyanate group } \\
\text { (completion of reaction } \\
\text { polymerization) }\end{array}$ \\
\hline
\end{tabular}

Langmuir isotherm: Langmuir equation is consider that the adsorption energy of each molecule is the same, independently of the surface material, the adsorption takes place only on some sites and there is no interaction between the molecules $^{53}$. Langmuir equation is applicable to homogeneous adsorption, where the adsorption of each molecule onto surface has equal adsorption activation energy and no transmigration of adsorbate in the plane of the surface $e^{4,54}$.

\section{Langmuir isotherm model:}

$$
\frac{\mathrm{C}_{\mathrm{e}}}{\mathrm{q}_{\mathrm{e}}}=\frac{\mathrm{C}_{\mathrm{e}}}{\mathrm{q}_{\mathrm{m}}}+\frac{1}{\mathrm{q}_{\mathrm{m}}}
$$

where, $C_{e}$ is the equilibrium concentration $(\mathrm{mg} / \mathrm{L}), \mathrm{q}_{\mathrm{e}}$ the amount of $\mathrm{Cr}$ sorbed at equilibrium $(\mathrm{mg} / \mathrm{g}), \mathrm{q}_{\mathrm{m}}$ is amount of Cr sorbed for a complete monolayer $(\mathrm{mg} / \mathrm{g})$, b is a constant related to the energy or net entalphy of sorption $(1 / \mathrm{mg})$. The graph plots of Langmuir model at different temperature are presented in Fig. 3a and 3b.

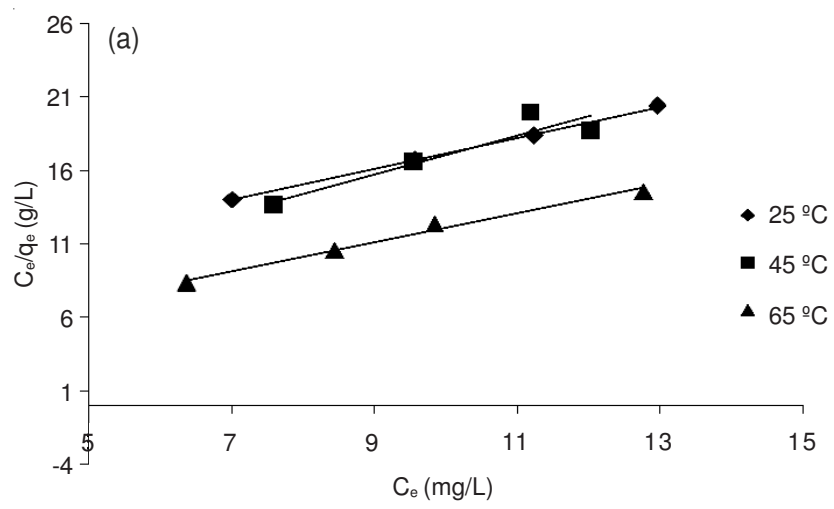




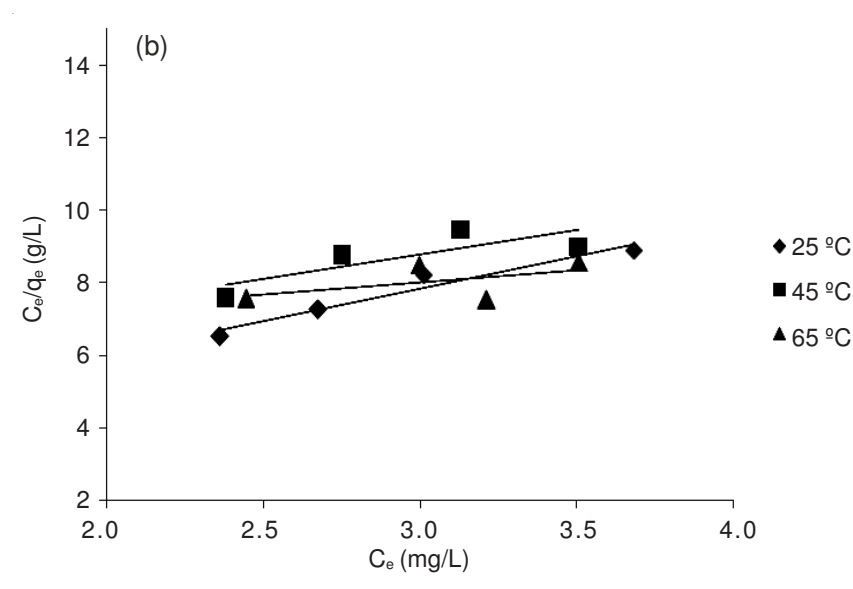

Fig. 3. Langmuir isotherm at different temperature for (a) $\beta$-CDP-HMDI, (b) $\beta$-CDP-TDI

Freundlich isotherm: Freundlich isotherm assumes that the uptake of metal ions occurs on a heterogeneous surface by multilayer adsorption and the amount of adsorbate adsorbed increases infinitely with an increase concentration ${ }^{11}$. Its application suggests that adsorption energy exponentially decreases on completion of the adsorption centre of an adsorbent. From the Freundlich isotherm of metal ion, it could be assumed that the stronger binding sites are occupied first and then the binding strength is decreased with increasing degree site occupation $^{55}$.

\section{Freundlich isotherm model:}

$$
\log \mathrm{q}_{\mathrm{e}}=\log \mathrm{k}_{\mathrm{f}}+\frac{1}{\mathrm{n}} \log \mathrm{C}_{\mathrm{e}}
$$

where, $\mathrm{k}_{\mathrm{f}}$ indicate adsorption capacity $(\mathrm{mg} / \mathrm{g})$ and $1 / \mathrm{n}$ is an empirical parameter related to the intensity of adsorption, which varies with the heterogeneity of the adsorbent, $\mathrm{q}_{\mathrm{e}}$ is amount of chromium sorbed at equilibrium $(\mathrm{mg} / \mathrm{g}), \mathrm{C}_{\mathrm{e}}$ is the equilibrium concentration $(\mathrm{mg} / \mathrm{L})$. The graph plots of Freundlich model at different temperature are shown in Fig. $4 \mathrm{a}$ and $4 \mathrm{~b}$.

From Table-2 it can be seen from the correlation coefficient $\left(\mathrm{R}^{2}\right)$ that the Langmuir model is fitting well for $\beta$-CDPHMDI, suggesting the monolayer coverage of $\mathrm{Cr}(\mathrm{VI})-\mathrm{DPC}$ complex onto particles and also the homogeneous distribution of active sites on the material. The adsorption phenomenon on $\beta$-CDP-HMDI seems to be caused by inclusion of $\mathrm{Cr}(\mathrm{VI})$ DPC complex into $\beta$-CDP-HMDI. However, Freundlich isotherm model is fitting well for $\beta$-CDP-TDI. It can be seen from correlation coefficient and suggesting the multilayer coverage of $\mathrm{Cr}(\mathrm{VI})$-DPC complex onto the particle and also heterogeneous distribution of active sites on the adsorbent. From the result, it shows that the type of bifunctional isocyanate linker plays important role to control the behaviour of adsorbate during adsorption process.

The value of $\mathrm{q}_{\mathrm{m}}$ increases with increase of the temperature from 25 to $65^{\circ} \mathrm{C}$. The increase in adsorption capacity with rise temperature may be is due to the increase in chemical interaction between adsorbate and sorbent surface ${ }^{10}$. This reveals the endothermic nature of the ongoing process.

Table-2 also showed that $\beta$-CDP-TDI has the higher adsorption capacity while $\beta$-CDP-HMDI has the lower adsorption capacity. $\beta$-CDP-TDI consists of aromatic ring and able to entrap $\mathrm{Cr}$ (VI)-DPC complex in polymer network due to the $\pi$ - $\pi$ interaction between toluene-2,4-diisocyanate and 1,5 -diphenylcarbazide. Therefore, the capacity of $\beta$-CDP-TDI is higher than $\beta$-CDP-HMDI.
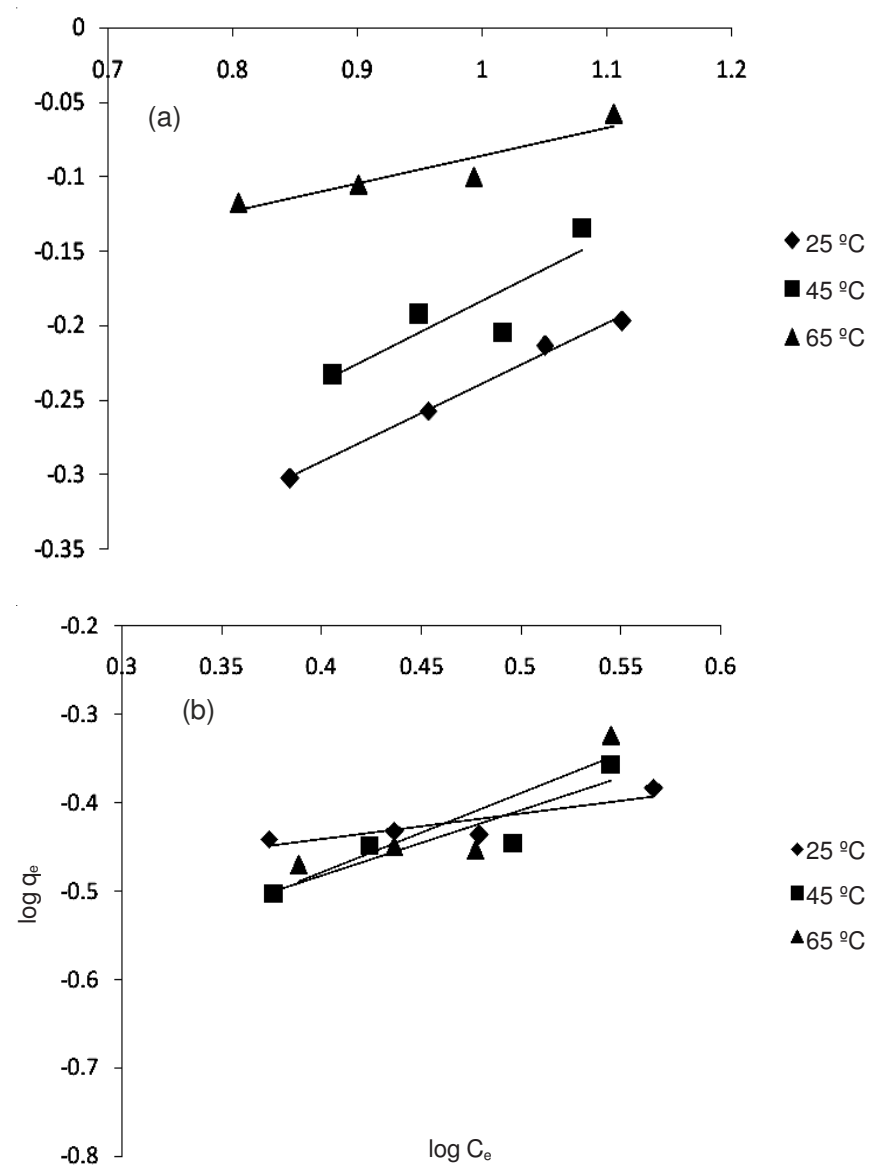

Fig. 4. Freundlich isotherm at different temperature for (a) $\beta$-CDP-HMDI, (b) $\beta$-CDP-TDI

TABLE-2

PARAMETERS OF LANGMUIR AND FREUNDLICH ISOTHERM FOR SORPTION Cr(VI)-DPC COMPLEX UPON DIFFERENT TYPES OF ADSORBENTS AND TEMPERATURE

\begin{tabular}{lcccc|ccc}
\hline \multirow{2}{*}{$\begin{array}{c}\text { Adsor- } \\
\text { bent }\end{array}$} & $\begin{array}{c}\text { Temp. } \\
\left({ }^{\circ} \mathrm{C}\right)\end{array}$ & $\begin{array}{c}\text { L } \\
(\mathrm{L} / \mathrm{mg})\end{array}$ & $\begin{array}{c}\mathrm{q}_{\mathrm{m}} \\
(\mathrm{mg} / \mathrm{g})\end{array}$ & $\mathrm{R}^{2}$ & $\mathrm{~K}_{\mathrm{f}}$ & $1 / \mathrm{n}$ & $\mathrm{R}^{2}$ \\
\hline \multirow{2}{*}{$\beta$-CDP- } & 25 & 0.9469 & 0.1596 & 0.9990 & 0.2275 & 0.4042 & 0.9942 \\
HMDI & 45 & 0.7564 & 0.3424 & 0.8640 & 0.2460 & 0.4260 & 0.773 \\
& 65 & 0.4250 & 1.0202 & 0.9855 & 0.5333 & 0.1870 & 0.8700 \\
\hline \multirow{2}{*}{$\beta$-CDP- } & 25 & 0.7273 & 0.5577 & 0.9430 & 0.2766 & 0.2920 & 0.7800 \\
TDI & 45 & 0.1065 & 0.7500 & 0.6320 & 0.1671 & 0.7379 & 0.8350 \\
& 65 & 0.037 & 3.6363 & 0.0820 & 0.1452 & 0.8990 & 0.7890 \\
\hline
\end{tabular}

The essential features of a Langmuir isotherm can be expressed in terms of a dimensionless constant equilibrium parameter, $\mathrm{R}_{\mathrm{L}}$ that is used to predict if an adsorption system is favourable or unfavourable. Thus, $\mathrm{R}_{\mathrm{L}}$ is a positive number whose magnitude determines the feasibility of the adsorption process. The equilibrium parameter $\mathrm{R}_{\mathrm{L}}$ was calculated using constant $b$ values from the following eqn. 4 :

$$
\mathrm{R}_{\mathrm{L}}=\frac{1}{\left(1+\mathrm{bC}_{\mathrm{o}}\right)}
$$


where, $\mathrm{C}_{0}$ is the initial $\mathrm{Cr}(\mathrm{VI})$ concentration $(\mathrm{mg} / \mathrm{L})$ and $\mathrm{b}$ is the Langmuir adsorption equilibrium constant $(\mathrm{L} / \mathrm{g})$. The isotherm is unfavourable when $\mathrm{R}_{\mathrm{L}}>1$, the isotherm is linear when $\mathrm{R}_{\mathrm{L}}=1$, the isotherm is favourable when $\mathrm{R}_{\mathrm{L}}<1$ and the isotherm is irreversible when $\mathrm{R}_{\mathrm{L}}=0$. The $\mathrm{R}_{\mathrm{L}}$ values at different temperature relating to the initial $\mathrm{Cr}(\mathrm{VI})$ ion concentration are given in Table-3.

\section{TABLE-3}

VALUES OF $R_{L}$ FOR BOTH ADSORBENTS AT DIFFERENT TEMPERATURE AND INITIAL CONCENTRATION OF Cr(VI) ION

\begin{tabular}{cccc|ccc}
\hline $\mathrm{C}_{\mathrm{o}}$ & \multicolumn{3}{c|}{$\beta$-CDP-HMDI } & \multicolumn{3}{c}{$\beta$-CDP-TDI } \\
\cline { 2 - 7 }$(\mathrm{mg} / \mathrm{L})$ & $25^{\circ} \mathrm{C}$ & $45^{\circ} \mathrm{C}$ & $65^{\circ} \mathrm{C}$ & $25^{\circ} \mathrm{C}$ & $45^{\circ} \mathrm{C}$ & $65^{\circ} \mathrm{C}$ \\
\hline 10 & 0.0955 & 0.1168 & 0.1905 & 0.1209 & 0.2638 & 0.4593 \\
15 & 0.0658 & 0.0810 & 0.1356 & 0.0840 & 0.1928 & 0.3616 \\
20 & 0.0502 & 0.0620 & 0.1053 & 0.0643 & 0.1519 & 0.2982 \\
25 & 0.0405 & 0.0502 & 0.0860 & 0.0521 & 0.1254 & 0.2536 \\
30 & 0.0340 & 0.0422 & 0.0727 & 0.0438 & 0.1067 & 0.2207 \\
\hline
\end{tabular}

The values of $\mathrm{R}_{\mathrm{L}}$ for adsorption of $\mathrm{Cr}(\mathrm{VI})$-DPC complex for both adsorbents studied at different initial concentration, temperatures and the values between 0 and 1 , which indicates favourable adsorption of $\mathrm{Cr}(\mathrm{VI})$-DPC complex on $\beta$-CDPHMDI and $\beta$-CDP-TDI. The $\mathrm{R}_{\mathrm{L}}$ values increase with increasing temperature. This indicates that sorption is more favourable at high temperature. In addition, the $\mathrm{R}_{\mathrm{L}}$ values decrease with increasing initial $\mathrm{Cr}(\mathrm{VI})$ ion concentration at all studied temperature indicates that sorption is more favourable at low concentration $^{20,56}$. From values of $\mathrm{R}_{\mathrm{L}}$ (Table-3), it is concluded that the adsorption of $\mathrm{Cr}(\mathrm{VI})$-DPC complex in $\beta$-CDP-TDI is more favourable than $\beta$-CDP-HMDI.

Sorption kinetic studies: The adsorption kinetic process of $\beta$-CDP-HMDI and $\beta$-CDP-TDI with $5 \mathrm{mg} / \mathrm{L}$ of $\mathrm{Cr}(\mathrm{VI})-$ DPC complex at different temperature $\left(25^{\circ} \mathrm{C}, 45^{\circ} \mathrm{C}\right.$ and $\left.65^{\circ} \mathrm{C}\right)$ is investigated and showed in Fig. 5a and 5b. The sorption increases instantly at initial stages. It may be due to rapid attachment of $\mathrm{Cr}(\mathrm{VI})$-DPC complex to the surface of the adsorbent and then increase gradually until equilibrium is reached and remains constant. The kinetic result indicates that the sorption process is very fast because of the largest amount of $\mathrm{Cr}$ (VI)-DPC complex adsorb to the adsorbent within $5 \mathrm{~min}$ and equilibrium reached within $60 \mathrm{~min}$.

Kinetic analysis is required to get an insight of the rate of adsorption and the rate limiting step of the transport mechanism, which are primarily used in the modelling and design of the process $^{57}$. The adsorption kinetic data of chromium are analyzed using the pseudo-first order kinetic and pseudosecond order kinetic equation ${ }^{58}$.

The equation of pseudo-first order kinetic model given as follows:

$$
\ln \left(\mathrm{q}_{\mathrm{e}}-\mathrm{q}_{\mathrm{t}}\right)=\ln \mathrm{q}_{\mathrm{e}}-\mathrm{k}_{1} \mathrm{t}
$$

where, $\mathrm{k}_{1}\left(\mathrm{~min}^{-1}\right)$ is the rate constant of pseudo first order sorption, $\mathrm{q}_{\mathrm{t}}$ denotes the amount of chromium sorption $(\mathrm{mg} / \mathrm{g}$ ) at time, $\mathrm{t}(\mathrm{min})$ and, $\mathrm{q}_{\mathrm{e}}$ denotes the amounts of chromium sorption $(\mathrm{mg} / \mathrm{g})$ at equilibrium. Values of $\mathrm{q}_{\mathrm{e}}$ and $\mathrm{k}_{1}$ were calculated from the slope of the plots of $\log \left(\mathrm{q}_{\mathrm{e}}-\mathrm{q}_{\mathrm{t}}\right)$ against $\mathrm{t}$. The graph plot of pseudo-first order kinetic model is shown in Fig. $6 \mathrm{a}$ and $6 \mathrm{~b}$.
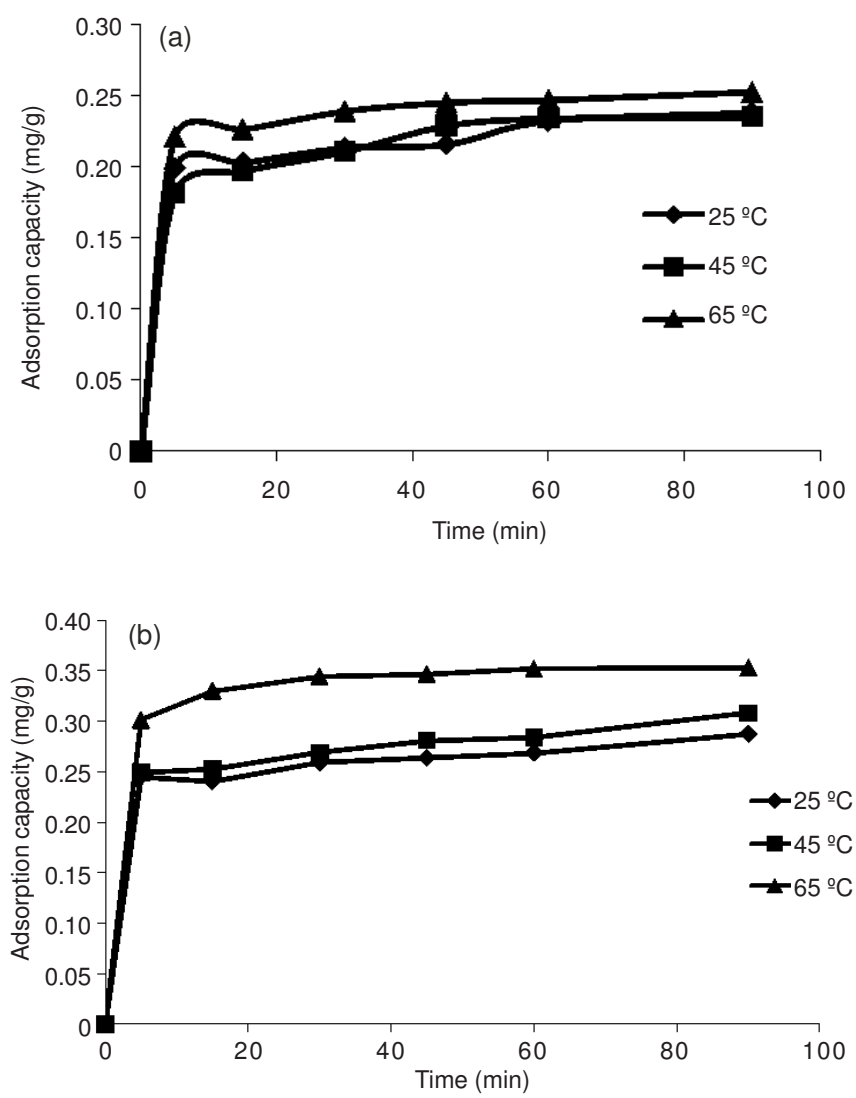

Fig. 5. Sorption kinetic of $\mathrm{Cr}(\mathrm{VI})$-DPC complex at different temperature on (a) $\beta$-CDP-HMDI, (b) $\beta$-CDP-TDI
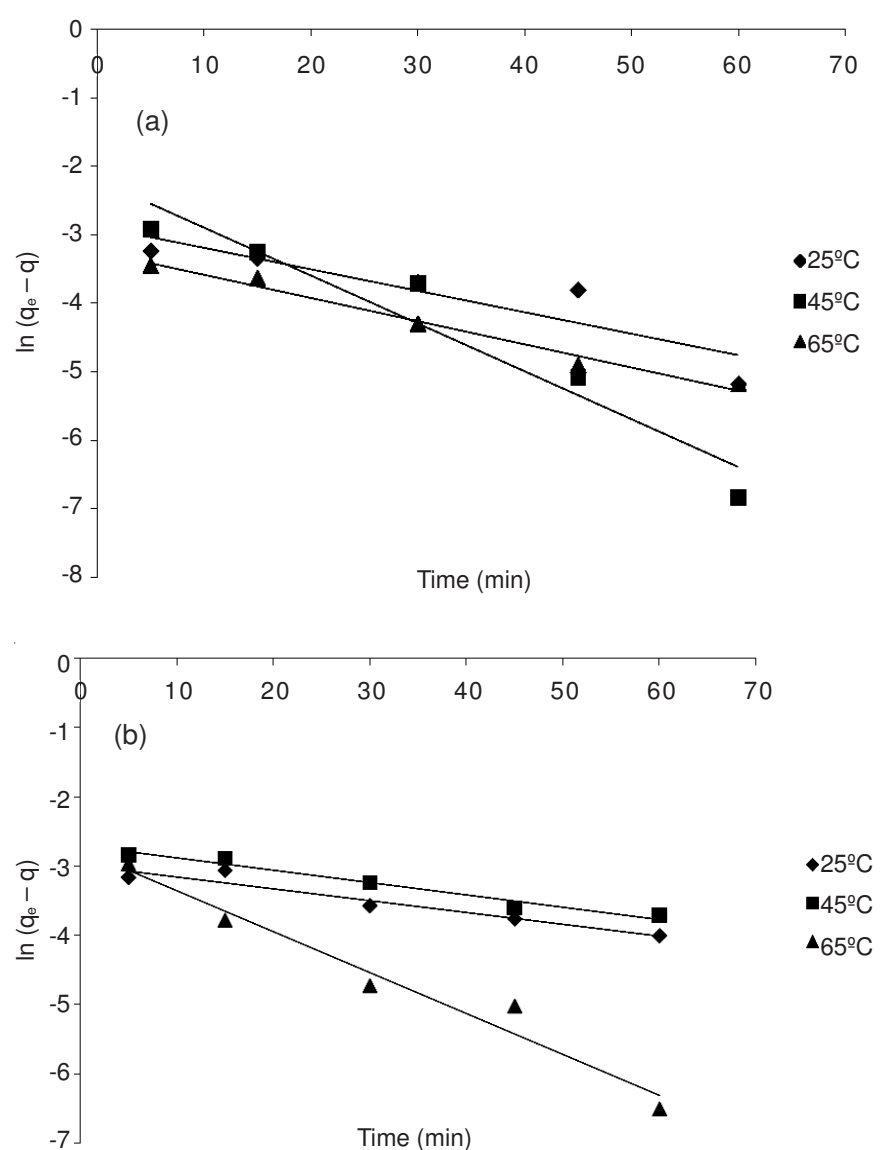

Fig. 6. Plot for pseudo-first order kinetic model for adsorption $\mathrm{Cr}$ (VI)-DPC complex on (a) $\beta$-CDP-HMDI and (b) $\beta$-CDP-TDI 
The equation of pseudo second order kinetic model given as follows:

$$
\frac{\mathrm{t}}{\mathrm{q}_{\mathrm{t}}}=\left(\frac{1}{\mathrm{k}_{2} \mathrm{q}_{\mathrm{e}}^{2}}\right)+\left(\frac{\mathrm{t}}{\mathrm{q}_{\mathrm{e}}}\right)
$$

where, $\mathrm{k}_{2}$ is the equilibrium rate constant of pseudo second order adsorption $\left(\mathrm{g} \mathrm{mg}^{-1} \mathrm{~min}^{-1}\right)$. Values of $\mathrm{k}_{2}$ and $\mathrm{q}_{\mathrm{e}}$ were calculated from the plot of $t / q$ against $t$. The graph of pseudosecond order kinetic model are exhibited in Fig. $7 \mathrm{a}$ and $7 \mathrm{~b}$ for adsorption of $\mathrm{Cr}(\mathrm{VI})-\mathrm{DPC}$ complex on $\beta$-CDP-HMDI and $\beta$-CDP-TDI, respectively.
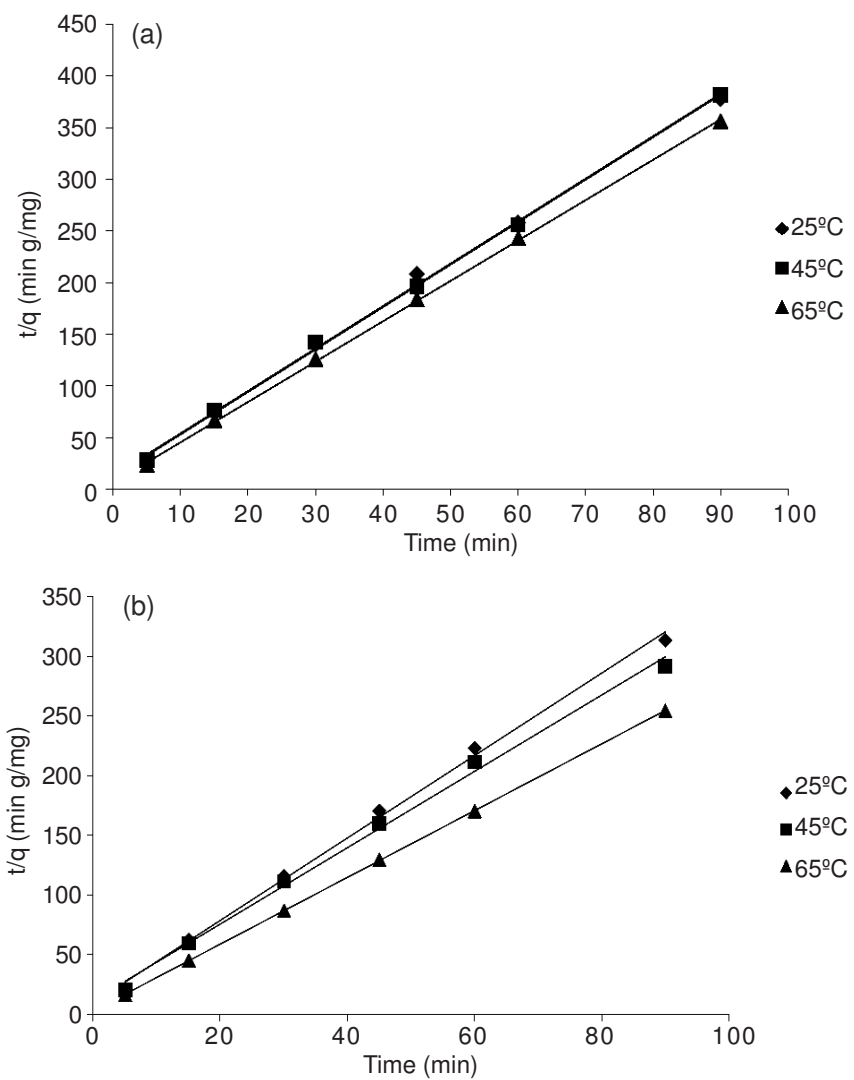

Fig. 7. Plot for pseudo-second order kinetic model for adsorption $\mathrm{Cr}(\mathrm{VI})$ DPC complex on (a) $\beta$-CDP-HMDI and (b) $\beta$-CDP-TDI

The straight line plots of pseudo-first order and pseudosecond order kinetic have been tested to obtain the kinetic parameters (Table-4). It can be seen from the correlation coefficients $\left(\mathrm{R}^{2}\right)$ that the adsorption for $\beta$-CDP-HMDI and $\beta$-CDP-TDI follow pseudo-second order model. The calculated $\mathrm{q}_{\mathrm{e}}$ values agree very well with the experimental data, indicates that the sorption system belongs to pseudo second order kinetic model. The rate constant for pseudo-second order increases with increasing temperature for both of adsorbents.

The $\beta$-CDP-TDI have lower rate constant than $\beta$-CDPHMDI. This is due to the presence of aromatic group in toluene2,4 -diisocyanate. The $\beta$-CDP-TDI is more hydrophobic than $\beta$-CDP-HMDI. As polymer in behaviour more hydrophobic, the diffusion of water is less and hence the contact between polymer and solute become slower ${ }^{37}$.

Adsorption thermodynamic parameters: Thermodynamic parameters such as enthalpy change $\left(\Delta \mathrm{H}^{\circ}\right)$, free energy change $\left(\Delta \mathrm{G}^{\mathrm{o}}\right)$ and entropy $\left(\Delta \mathrm{S}^{\mathrm{o}}\right)$ can be estimated using equilibrium constants changing with temperature. The standard free energy change of the sorption reaction is given by the following equation 5 .

$$
\Delta \mathrm{G}^{\mathrm{o}}=-\mathrm{RT} \ln \mathrm{K}_{\mathrm{d}}
$$

where, $\mathrm{R}$ is the ideal gas constant $\left(8.314 \mathrm{~J} \mathrm{~mol}^{-1} \mathrm{~K}^{-1}\right)$ and $\mathrm{T}$ is the temperature $(\mathrm{K})$.

In this case, the activity should be instead of concentration in order to obtain the standard thermodynamic equilibrium constant $\left(\mathrm{K}_{\mathrm{d}}\right)$ of the adsorption system.

$$
\ln \mathrm{K}_{\mathrm{d}}=-\frac{\Delta \mathrm{G}^{\mathrm{o}}}{\mathrm{RT}}=-\frac{\Delta \mathrm{H}^{\mathrm{o}}}{\mathrm{RT}}+\frac{\Delta \mathrm{S}^{\mathrm{o}}}{\mathrm{R}}
$$

Fig. 8 shows the graph of $\ln \mathrm{K}_{\mathrm{d}} v s .1 / \mathrm{T}$. The value of $\Delta \mathrm{H}^{\circ}$ and $\Delta \mathrm{S}^{\circ}$ can be calculated from the slope and intercept, respectively. The value of parameters of thermodynamic is shown in Table-5.

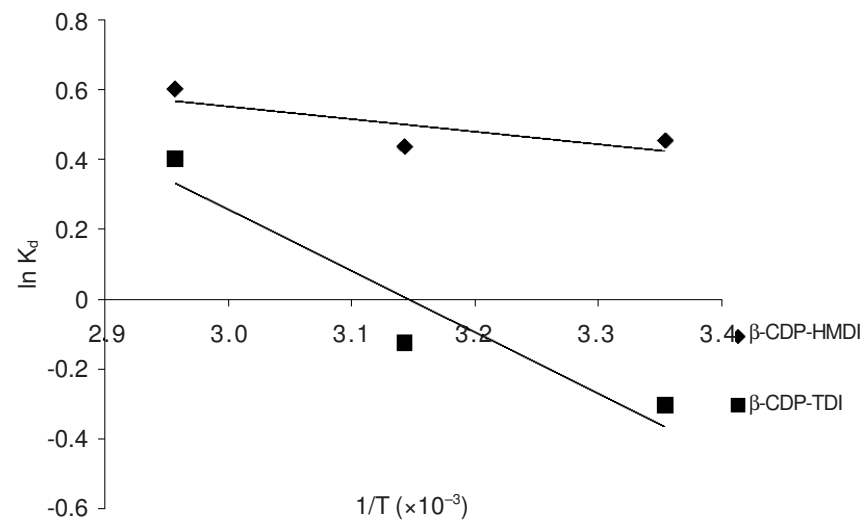

Fig. 8. Plot of $\ln \mathrm{K}_{\mathrm{d}} v s .1 / \mathrm{T}$ for both of adsorbents

The negative values of free energy change $\left(\Delta G^{\circ}\right)$ at all temperature indicates thermodynamically feasible and

TABLE-4

KINETIC PARAMETERS FOR PSEUDO-FIRST ORDER AND PSEUDO-SECOND ORDER KINETIC

\begin{tabular}{cccccc|ccc}
\hline Adsorbent & Temperature & $\mathrm{q}_{\mathrm{e}}$ exp & \multicolumn{2}{c|}{ Pseudo first order kinetic model } & \multicolumn{3}{c}{ Pseudo second order kinetic model } \\
\cline { 5 - 9 } & $\left({ }^{\circ} \mathrm{C}\right)$ & $(\mathrm{mg} / \mathrm{g})$ & $\mathrm{k}_{1} \times 10^{-2}\left(\mathrm{~min}^{-1}\right)$ & $\mathrm{q}_{\mathrm{e}}$ cal $(\mathrm{mg} / \mathrm{g})$ & $\mathrm{R}^{2}$ & $\mathrm{k}_{2} \times 10^{-2}(\mathrm{~g} / \mathrm{mg} \min )$ & $\mathrm{q}_{\mathrm{e}} \mathrm{cal}(\mathrm{mg} / \mathrm{g})$ & $\mathrm{R}^{2}$ \\
\hline \multirow{2}{*}{$\beta$-CDP- } & 25 & 0.2380 & 3.1000 & 0.0560 & 0.8080 & 136.6400 & 0.2430 & 0.9970 \\
HMDI & 45 & 0.2350 & 6.9000 & 0.1110 & 0.9280 & 138.8000 & 0.2450 & 0.9990 \\
& 65 & 0.2520 & 3.3000 & 0.0390 & 0.9800 & 237.8000 & 0.2560 & 0.9990 \\
$\beta$-CDP- & 25 & 0.2870 & 1.7000 & 0.0510 & 0.9270 & 117.7500 & 0.2900 & 0.9970 \\
TDI & 45 & 0.3080 & 1.7000 & 0.0670 & 0.9650 & 89.3500 & 0.3120 & 0.9950 \\
& 65 & 0.3530 & 5.9000 & 0.0640 & 0.9630 & 247.3400 & 0.3680 & 1.0000 \\
\hline
\end{tabular}


spontaneous nature of the adsorption of $\mathrm{Cr}(\mathrm{VI})-\mathrm{DPC}$ complex on all adsorbents. The values of $\Delta \mathrm{G}^{\mathrm{o}}$ varied in range of -15.566 to $-4.084 \mathrm{~kJ} / \mathrm{mol}$. The change of the standard free energy decreases with increasing temperature, suggests due to the more absorbable of $\mathrm{Cr}(\mathrm{VI})$-DPC complexes with increases temperature and also shows a decrease in feasibility of adsorption at higher temperature ${ }^{59,60}$. $\beta$-CDP-TDI is more absorbable of $\mathrm{Cr}(\mathrm{VI})$-DPC complexes than $\beta$-CDP-HMDI. The positive values of $\Delta \mathrm{H}^{\circ}$ varied in the range of 3.03-9.98 $\mathrm{kJ} / \mathrm{mol}$, suggests the endothemic nature of adsorption.

\section{TABLE-5}

THERMODYNAMIC PARAMETERS OF ADSORBENT

\begin{tabular}{ccccc}
\hline Adsorbent & $\begin{array}{c}\text { Temp. } \\
\left({ }^{\circ} \mathrm{C}\right)\end{array}$ & $\begin{array}{c}\text { Enthalpy } \\
\left(\Delta \mathrm{H}^{\circ}\right) \\
(\mathrm{kJ} / \mathrm{mol})\end{array}$ & $\begin{array}{c}\text { Entropy } \\
\left(\Delta \mathrm{S}^{\circ}\right) \\
(\mathrm{J} / \mathrm{Kmol})\end{array}$ & $\begin{array}{c}\text { Gibbs energy } \\
\left(\Delta \mathrm{G}^{\circ}\right) \\
(\mathrm{J} / \mathrm{mol}) \times 10^{3}\end{array}$ \\
\hline \multirow{2}{*}{$\beta$-CDP- } & 25 & & & -4.084 \\
HMDI & 45 & \multirow{2}{*}{3.026} & 13.709 & -4.358 \\
& 65 & & & -4.636 \\
\hline \multirow{2}{*}{$\beta$-CDP- } & 25 & & & -13.723 \\
TDI & 45 & \multirow{2}{*}{14.649} & 46.079 & -14.645 \\
& 65 & & & -15.566 \\
\hline
\end{tabular}

In addition, the low values of $\Delta \mathrm{H}^{\mathrm{o}}$ indicate that there was loose of bonding between the adsorbate molecules and adsorbent surface $^{61,62}$. Table-5 shows that $\beta$-CDP-TDI has the highest value of $\Delta \mathrm{H}^{\mathrm{o}}$ and it reveals the presence of strong chemical bond with $\mathrm{Cr}(\mathrm{VI})-\mathrm{DPC}$ complex. The heat of adsorption, which ranging from 0.5 to $5 \mathrm{kcal} / \mathrm{mol}(2.1-20.9 \mathrm{~kJ} / \mathrm{mol})$, represent a physical adsorption and the heat of adsorption ranging from 5$100 \mathrm{kcal} / \mathrm{mol}(20.9-418.4 \mathrm{~kJ} / \mathrm{mol})$, represent a chemical sorption ${ }^{63}$. The values of $\Delta \mathrm{H}^{\mathrm{o}}$ for both adsorbents within the range 3.03$9.98 \mathrm{~kJ} / \mathrm{mol}$, indicating the type of adsorption is physiosorption.

The positive values of $\Delta \mathrm{S}^{\circ}$ for both adsorbents are in range of $13.71-46.08 \mathrm{~kJ} / \mathrm{K}$ mol. It shows the increasing randomness at the solid/solution interface during the adsorption process. It suggests that $\mathrm{Cr}(\mathrm{VI})$ ions replace some water molecules from the solution previously adsorbed on the surface of adsorbent. These displaced molecules gain more translation entropy than is lost by the absorbate ions, thus allowing the prevalence of randomness in the system ${ }^{58,64}$. In addition, the positive entropy of adsorption reflects the affinity of the adsorbent material towards $\mathrm{Cr}$ (VI)-DPC complex ${ }^{65}$. From the values of entropy, it shows that $\beta$-CDP-TDI has the highest affinity of the adsorbent material towards the $\mathrm{Cr}(\mathrm{VI})$-DPC complex than $\beta$-CDPHMDI.

\section{Conclusion}

In this study, $\beta$-CDP adsorbents were used for adsorption of $\mathrm{Cr}$ (VI)-DPC complex. The adsorption isotherm and kinetics of both adsorbents were studied. From the trends of parameter of adsorption capacity, rate constant and thermodynamic parameter, it reveals that the type of crosslinker is main factor contributes in the adsorption process. In this study, toluene2,4-diisocyanate which consist aromatic group enhance the adsorption process due to the $\pi$ - $\pi$ interaction between toluene2,4-diisocyanate and 1,5-diphenylcarbazide. This aromatic group also decrease the rate of uptake since it is more hydrophobic compared to the aliphatic crosslinker, 1,6-hexameth-ylene diisocyanate.

\section{ACKNOWLEDGEMENTS}

The authors acknowledged the University of Malaya for the financial support through Fundamental Grant. FS345/ 2008A, University Malaya Research Grant RG055/09SUS and also to Postgraduate Research Fund (PPP) through grant PS 336/2009B.

\section{REFERENCES}

1. J. Kotas and Z. Stasicka, Environ. Pollut., 107, 263 (2000).

2. K. Selvaraj, S. Manonmani and S. Pattabhi, Bioresour. Technol., 89, 207 (2003).

3. F.N. Acar and E. Malkoc, Bioresou. Technol., 94, 13 (2004).

4. E. Pehlivan and S. Cetin, J. Hazard. Mater, 163, 448 (2009).

5. E. Malkoc and Y. Nuhoglu, Chem. Eng. Proc.: Proc. Intensificat., 46, 1020 (2007).

6. B. Benguella and H. Benaissa, Water Res., 36, 2463 (2002).

7. W.S. Wan Ngah, C.S. Endud and R. Mayanar, React. Funct. Polym., 50, 181 (2002).

8. G. Crini, Dyes Pigments, 77, 415 (2008).

9. R.M. Schneider, C.F. Cavalin, M.A.S.D. Barros and C.R.G. Tavares, Chem. Eng. J., 132, 355 (2007).

10. D.D. Das, R. Mahapatra, J. Pradhan, S.N. Das and R.S. Thakur, J. Colloid Interf. Sci., 232, 235 (2000).

11. T. Karthikiyen, S. Rajhgopal and L.R. Miranda, J. Hazard. Mater. B124, 192 (2005).

12. C. Raji and S. Anirudhan, Water Res., 32, 3772 (1998).

13. N. Tewari, P. Vasudevan and B.K. Guha, Biochem. Eng. J., 23, 185 (2005).

14. K.G. Bhattacharyya and S.S. Gupta, Ing. Eng. Chem. Res., 45, 7232 (2006).

15. M. Uysal and I. Ar, J. Hazard. Mater, 149, 482 (2007).

16. M.H. Isa, N. Ibrahim, H.A. Aziz, M.N. Adlan, N.H.M. Sabiani, A.A.L. Zinatizadeh and S.R.M. Kutty, J. Hazard. Mater., 152, 662 (2008).

17. C. Namasivayam and M.V. Sureshkumar, Bioresour. Technol., 99, 2218 (2008).

18. D. Zhou, L. Zhang, J. Zhou and S. Guo, Water Res., 38, 2643 (2004).

19. X. Zhu, M. Wu and Y. Gu, Talanta, 78, 565 (2009).

20. Y.A. Aydin and N.D. Aksoy, Chem. Eng. J., 151, 188 (2009)

21. E.M. Martin Del Valle, J. Proc. Biochem., 39, 1033 (2004).

22. G. Astray, C. Gonzalez-Barreiro, J.C. Mejuto, R. Rial-Otero and J. Simal-Gándara, Food Hydrocolloids, 23, 1631 (2009).

23. M. Prabaharan and J.F. Mano, Carbohyd. Polym., 63, 153 (2006).

24. B.B. Mamba, R.W. Krause, T.J. Malefetse and E.N. Nxumalo, Environ. Chem. Lett., 5, 79 (2007).

25. A. Ponchel, S. Abramson, J. Quartararo, D. Bormann, Y. Barbaux and E. Monflier, Micropor. Mesopor. Mater, 75, 261 (2004).

26. E.Y. Ozmen and M. Yilmiz, J. Hazard. Mater, 148, 303 (2007).

27. G. Crini, H.N. Peindy, F. Gimbert and C. Robert, Sep. Purif. Technol., 53, 97 (2007).

28. A. Yilmaz, E. Yilmaz and M. Yilmaz, Dyes Pigments, 74, 54 (2007).

29. D. Zhao, L. Zhao and C.-S. Zhu, J. Incl. Phenom. Macrocycl. Chem., 63, 195 (2009).

30. N. Li, X. Xiong and R. Li, Bull. Chem. Soc. Japan, 59, 507 (2009).

31. S. Shiraishi, M. Komiyama and H. Hirai, (1986).

32. Y. Fan, Y. Feng and S. Da, Anal. Chim. Acta, 484, 145 (2003).

33. L. Janus, G. Crini, V. El-Rezzi, M. Morcellet, A. Cambiaghi, G. Torri, A. Naggi and C. Vecchi, React. Funct. Polym., 42, 173 (1999).

34. T.N.T. Phan, M. Bacquet and M. Morcellet, React. Funct. Polym., 52, 117 (2002).

35. N. Aoki, M. Nishikawa and K. Hattori, Carbohyd. Polym., 52, 219 (2003).

36. F. Zha, S. Li and Y. Chang, Carbohyd. Polym., 72, 456 (2008).

37. Y.P. Chin, S. Mohamad and M.R. Abas, Int. J. Mol. Sci., 11, 3459 (2010).

38. M. Kitaoka and K. Hayashi, J. Incl. Phenom. Macrocycl. Chem., 44, 429 (2002).

39. Y. Shao, B. Martel and M. Morcellet, J. Incl. Phenom. Macrocycl. Chem., 25, 209 (1996).

40. G. Crini, S. Bertini and G. Torri, A. Naggi, D. Sforzini, C. Vecchi, L. Janus, Y. Lekchiri and M. Morcellet, J. Appl. Polym. Sci., 68, 1973 (1998). 
41. T. Gu, G. Tsai and G.T. Tsao, J. Incl. Phenom. Macrocycl. Chem., 56, 375 (2006)

42. T.C. Werner, J.L. Iannacone and M.N. Amoo, J. Incl. Phenom. Macrocycl. Chem., 25, 77 (1996).

43. E.Y. Ozmen, A. Sirit and M. Yilmaz, J. Macromol. Sci., A 44, 167 (2007).

44. K. Sreenivasan, Angew. Macromol. Chem., 235, 15 (1996).

45. H. Yamasaki, Y. Makihata and K. Fukunaga, J. Chem. Technol. Biotechnol., 83, 991 (2008)

46. Y. El Ghoul, B. Martel and M. Morcellet, J. Incl. Phenom. Macrocycl. Chem., 57, 47 (2007).

47. L. Ducoroy, B. Martel and B. Bacquet, J. Incl. Phenom. Macrocycl. Chem., 57, 271 (2007).

48. B. Martel, M. Morcellet and D. Ruffin, J. Incl. Phenom. Macrocycl. Chem., 44, 443 (2002).

49. P. Lo Nostro, L. Fratoni and P. Baglioni, J. Incl. Phenom. Macrocycl. Chem., 44, 423 (2002).

50. S. Berto, M.C. Bruzzoniti and R. Cavalli, J. Incl. Phenom. Macrocycl. Chem., 57, 631 (2007).

51. S. Berto, M.C. Bruzzoniti and R. Cavalli, J. Incl. Phenom. Macrocycl. Chem., 57, 637 (2007)
52. M. Bhaskar, P. Aruna, R.G. Jeevan and G. Radhakrishnan, Anal.Chim. Acta, 509, 39 (2004)

53. F. Granados-Correa and J. Jimenez-Becerril, J. Hazard. Mater, 162, 1178 (2009).

54. J. Monika, V.K. Garg and K. Kadirvelu, J. Hazard. Mater, 162, 365 (2009).

55. E. Pehlivan, S. Cetin and B.H. Yanik, J. Hazard. Mater., B135, 193 (2006).

56. A. Mittal, L. Kurup and J. Mittal, J. Hazard. Mater., 146, 243 (2007).

57. A.A. Yasar and N.D. Aksoy, Chem. Eng. J., 151, 188 (2009).

58. E. Malkoc and Y. Nuhoglu, Sep. Purif. Technol., 54, 291 (2007).

59. B. Karagozoglu, M. Tasdemir, E. Demirbas and M. Kobya, J. Hazard. Mater., 147, 297 (2007).

60. A. Sari and M. Tuzen, J. Hazard. Mater, 160, 349 (2008).

61. D. Singh, Adsorp. Sci. Tech., 18, 741 (2000).

62. A. Ozcan, E.M. Oncu and A.S. Ozcan, Colloids. Surf. A, 277, 90 (2006).

63. D.Y. Liping, H. Su, X. Su, Wang and X. Zhu, J. Hazard. Mater, 143, 220 (2007)

64. K.G. Vinod, M. Dinesh, S. Saurabh and T.P. Kuk, The Environmentalist, 19, 129 (1999).

65. S. Chegrouche, A. Mellah and M. Barkat, Desalination, 235, 306 (2009). 